\title{
O AMBIENTE NATURAL DE NOSSAS SOCIEDADES
}

Resenha de: GUATTARI, Félix. As três ecologias. Tradução Maria Cristina F. Bittencourt. 21 ed. Campinas, SP: Papirus, 2012.

\section{Débora de Sá Ribeiro Aymoré1 \\ http://orcid.org/0000-0003-1384-6681 \\ http://lattes.cnpq.br/5444018172944089}

Recebido em: 17 de junho de 2020

Aprovado em: 19 de agosto de 2020

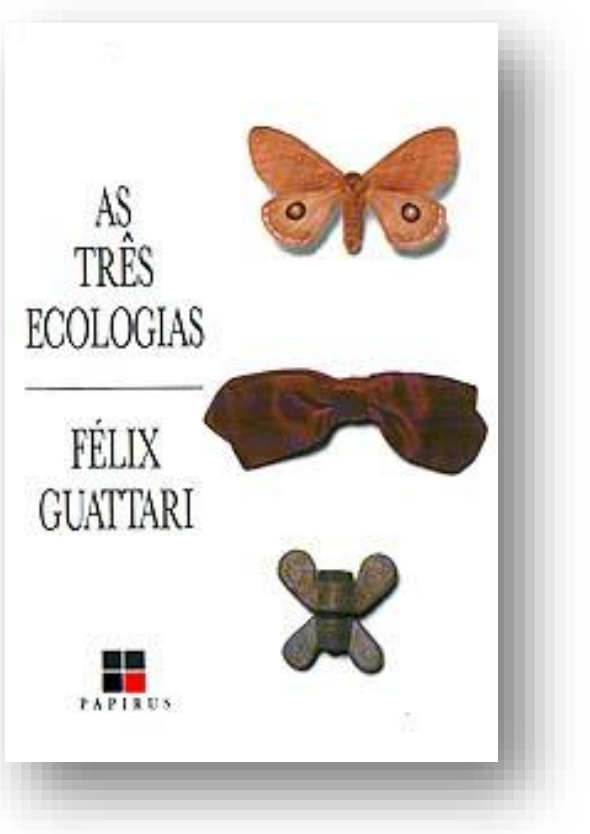

Originalmente publicada em 1990, a obra As três ecologias de Félix Guattari, ganha fôlego novo no século XXI, coincidentemente, com a publicação de sua $21^{\mathrm{a}}$ edição no Brasil. A despeito de sua curta extensão (cerca de 50 páginas na tradução brasileira), a obra ganha em abrangência ao propor que as soluções para as crises ambientais não dizem respeito apenas às iniciativas em prol da proteção da bioesfera ou ecoesfera (cf. HEYWOOD, 2010, p. 48), suficientemente transformada pela ciência e pela tecnologia em mecanoesfera (cf. GUATTARI, 2012, p. 52). Ao contrário, a proposta da Guattari dirige-se à formação do que denomina "ecosofia", que não se dedica apenas ao reconhecimento do desequilíbrio natural do ambiente materialmente considerado, mas avança na constituição de uma práxis condizente, inclusive, com a reelaboração imaterial (ou do imaginário).

Para melhor compreendermos a proposta, cabe enunciar as três ecologias a que o título de sua obra se refere, que são as ecologias mental, social e ambiental. No que segue enfatizaremos principalmente as duas primeiras, tomando como pressuposto que vivenciamos na contemporaneidade uma crise ambiental que, por si só, é merecedora de nossos esforços para a manutenção do equilíbrio necessário para a manutenção da vida humana e não humana na biosfera. Nossa ênfase nas duas primeiras formas de ecologia, na verdade, parece encontrar justificativa no próprio texto do autor, na medida em que sem a renovação no âmbito das mentalidades, novas práticas sociais correm o risco de incorrer no jogo do universo semiótico capitalista, que produz subjetividades que se voltam aos valores do rendimento e do lucro, em que o "[...] consumo tomou lugar daquilo que antes era cidadania" (KRENAK, 2019, p. 24).

Enquanto a ecologia científica, ramo da biologia que estuda as “[...] relações entre os orga-

${ }^{1}$ Mestre em Filosofia (USP, 2010), Doutora em Filosofia (USP, 2015) com estágio de pesquisa no exterior com bolsa CAPES (University of Miami, FL, 2013-2014), Pós-doutorado (USP, 2017 - 2018), Professora Substituta do curso de Filosofia da Universidade do Estado do Amapá (UEAP, 2017 - 2019), Professora Substituta do curso de Filosofia da Universidade Federal do Paraná (UFPR, 2019 - atual). E-mail: deboraaymore@gmail.com. 
nismos vivos e o meio ambiente" enfatizando a "[...] rede de relações que sustenta todas as formas de vida" (HEYWOOD, 2010, p. 48), propondo, deste modo, a investigação das relações de interdependência que as diferentes espécies mantém entre si e em relação à bioesfera, os seres humanos estariam inseridos nesta dinâmica que é parte da natureza. No entanto, além de seu aspecto biológico que o faz participar da cadeia de necessidades e de adaptações para a sobrevivência, o ser humano também produz uma vivência existencial, dirigindo as suas ações para a realização de valores. Assim, ao sofrermos as consequências da crise ambiental predispomo-nos à reflexão, por um lado, sobre a consideração da natureza como matéria prima, e, por outro lado, a supor outros modos de vida mais equilibrados.

Deste modo, a menos que, por nascimento, façamos parte de alguma comunidade tradicional, cujos relatos demonstram mais sensibilidade em relação às consequências do descolamento da terra (cf. KRENAK, 2019, p. 21), produzido pela modernidade, os habitantes das cidades urbanizadas podem cultivar pelo menos duas sensibilidades: a saudade em relação à conexão intuída com a natureza e o estranhamento em relação à vida citadina. Não sendo excludentes entre si, e possivelmente acompanhadas de outras emoções (ansiedades, medo, solidão etc.), as experiências emocionais negativas conformam conjuntos difusos de indícios da redução dos seres humanos ao papel de consumidores e limitam a existência, que impossibilita o sentimento e as ações de solidariedade. Eis que a expressão "[...] ambiente natural de nossas sociedades" (GUATTARI, 2012, p. 8) não se aplica exclusivamente aos territórios que ainda não foram transformados em mecanoesfera, mas torna-se aplicável especialmente às cidades.

Mesmo assim, é difícil esconder o incômodo diante da expressão de Guattari que correlaciona o ambiente natural e as sociedades construídas histórica e socialmente por seres humanos, por nos colocar diante de uma aparente confusão de categorias, uma vez que estamos acostumados com a dicotomia entre o natural e o artificial. Desde a modernidade as fronteiras entre este par dicotômico tornaram-se cada vez mais próximas, de tal modo que a transformação que a ciência e a tecnologia foram capazes de produzir na natureza pressuporia a ação humana com vistas à manutenção do equilíbrio apropriado para a vida humana. As categorias analíticas representadas pela dicotomia entre o natural e o artificial poderiam interseccionar. Ao menos é esta a impressão que temos a partir da proposta da ecosofia que, segundo Guattari, pretende a produção de bens materiais e imateriais, considerando os três registros ecológicos: o mental, que diz respeito à subjetividade humana, o social, que diz respeito às relações de sociabilidade e o ambiental, que se refere mais diretamente ao meio ambiente (cf. GUATTARI, 2012, p. 8 - 9).

Antes de especificarmos a solução proposta de Guattari, é preciso explorar de que modo o autor considera que o imaterial (o imaginário ou o simbólico) teria algo a contribuir para a constituição de práticas humanas material e existencialmente mais significativas e produtoras de equilíbrio em substituição à crise ambiental globalizada.

\section{UMA HISTÓRIA RECENTE DA MODERNIDADE}

Guattari faz um histórico recente da modernidade, considerando-nos herdeiros de antagonismos próprios do século XIX, dentre os quais destaca o antagonismo entre o Leste e o Oeste e entre a burguesia e o proletariado. Segundo o autor, estes antagonismos polarizaram nossa subjetividade que, no século XX, encontra no welfare, na mídia e na sociedade do consumo, a 
produção de um reconhecimento difuso de pertinência social. No entanto, assevera que a relação entre o Norte e o Sul não melhorou, em que se mantêm situações de hiperexploração (cf. GUATTARI, 2012, p. 11 - 12). Entremeando esta relação de pertinência social difusa estariam a ciência e a tecnologia que precisaria voltar-se para outros objetivos, diversos da economia do lucro, na medida em que,

[...] de um lado, o desenvolvimento contínuo de novos meios técnico-científicos potencialmente capazes de resolver problemas ecológicos dominantes e determinar o reequilíbrio das atividades socialmente úteis sobre a superfície do planeta e, de outro lado, a incapacidade de forçar sociais organizadas e das formações subjetivas constituídas de se apropriarem desses meios para tornálos operativos (GUATTARI, 2012, p. 12).

Instauram-se, então, antagonismos transversais, sem necessariamente seguir as oposições dualistas, e que, em sua multipolarização impedem a adesão de potenciais participantes, tal como no caso do fenômeno da "terceiro-mundialização interna dos países desenvolvidos" (GUATTARI, 2012, p. 13), das relações entre os homens e as mulheres que mantêm a exploração do trabalho feminino, bem como no caso da juventude que recebe por vezes da mídia a formação da subjetividade (cf. GUATTARI, 2012, p. 12 - 13).

A partir da multipolarização dos antagonismos a ecosofia social pretende a "[...] reconfiguração da práxis humanas nos mais variados domínios, buscando modificar e reinventar maneiras de ser no seio do casal, da família, do contexto urbano, do trabalho" (GUATTARI, 2012, p. 15). Não se trata, portanto, de buscar somente no estreitamento com o contato com a natureza a solução dos problemas ambientais e existenciais, mas de tornar nossas relações sociais mais significativas.

\section{ENQUANTO ISSO, A SUBJETIVIDADE...}

A partir da psicanálise e da concepção do inconsciente, o sujeito passa a não ser mais transparente para si próprio. A interioridade do indivíduo, além disso, se forma sob a influência de múltiplos componentes, por vezes discordantes entre si. Guattari propõe que nos desapeguemos das metáforas dos cientistas, obtidas da termodinâmica, da topologia, da teoria da informação, entre outros, suscitando novos significados com inspiração ético-estética (cf. GUATTARI, 2012, p. 15).

Exemplos de modelos de subjetivação da subjetividade são encontrados nas narrativas do teatro grego, do amor cortês e dos teatros de cavalaria. Neste ponto de sua exposição, Guattari critica a estrutura dos complexos em Psicanálise, que trilha, segundo o autor, o caminho do dogmatismo. Torna-se necessário, ao invés de ressaltar possíveis mecanismos inconscientes, ressaltar a responsabilidade e o engajamento (cf. GUATTARI, 2012, p. 20 - 21).

Objetivamente, Guattari considera que esta recomposição das práticas deve ser realizada individual e socialmente, mantendo a atenção nas três rubricas da ecologia (mental, social e ambiental) e que a sua recusa é provocada, inclusive, por um processo de infantilização e de neutralização da democracia (cf. GUATTARI, 2012, p. 24), processo o qual não é abordado em profundidade na obra.

Em nosso contexto, para Guattari: “Não somente as espécies desaparecem, mas também as palavras, as frases, os gestos de solidariedade humana” (GUATTARI, 2012, p. 24). O indivíduo, abandonado a si mesmo e desenraizado torna-se presa do capitalismo pós-industrial 
que, subjetivamente, passa a

[...] descentrar seus focos de poder das estruturas de produção de bens e de serviços, para as estruturas produtoras de signos, de sintaxes e de subjetividade, por intermédio especialmente, do controle que exerce sobre a mídia, a publicidade, as sondagens etc. (GUATTARI, 2012, p. $31)$.

É preciso, deste modo, propor alternativas para a ecologia mental e, quanto às práticas, que sejam efetivas nas micropolíticas e nas microssociedades, nas quais se juntam as "[...] novas solidariedades, uma nova suavidade justamente com novas práticas estéticas e novas práticas analíticas das formações do inconsciente" (GUATTARI, 2012, p. 35). Nota-se, assim, que é a partir das práticas sociais e políticas que emergem os modos alternativos ao universo semiótico capitalista.

\section{NOVOS TERRITÓRIOS EXISTENCIAIS? AS TRÊS ECOLOGIAS}

Conforme enunciado, Guattari propõe que compreendamos essa reconstrução do imaterial e da subjetividade, tendo em vista novas práticas sociais. A ecosofia, por sua vez, se estrutura a partir de três ecologias:

1. Ecologia mental: propõe a elaboração de outros significados para as atividades humanas, sejam elas no âmbito da cultura, do trabalho ou do cotidiano, que não restrinjam ao rendimento e ao lucro (cf. GUATTARI, 2012, p. 42).

2. Ecologia social: propõe o investimento afetivo e pragmático em agrupamentos humanos, evitando a reprodução de hiatos, tais como entre as elites e as classes sujeitadas (cf. GUATTARI, 2012, p. 45 - 46).

3. Ecologia ambiental: pressupondo a possibilidade de catástrofes e de soluções, reconhece que o equilíbrio natural é cada vez mais dependente da intervenção humana (cf. GUATTARI, 2012, p. 52).

Embora consideremos difícil avaliar a aplicabilidade da proposta de Guatarri, considerando a amplitude (ecologias mental, social e ambiental) e a causalidade estabelecida entre a conformação de subjetividades mais solidárias e a formação de práticas sociais mais equilibradas, a leitura desta obra enriquece criativamente a discussão sobre as soluções possíveis para a crise ambiental da modernidade.

A dúvida sobre a aplicabilidade se instaura, provavelmente, devido ao materialismo epistêmico e à estreita interdependência que a modernidade estabeleceu com a ciência e a tecnologia, expondo uma tensão na proposta de Guattari: os aparatos tecnocientíficos são apontados como causa das crises ambientais, por sua vinculação ao aos objetivos do capitalismo pósindustrial; e, ao mesmo tempo, considerados fonte possível de solução para a crise ambiental.

Parece-nos que esta tensão não retira a criatividade que emana deste texto, especialmente por levantar a hipótese segundo a qual o imaterial pode manter relação causal de reforço mútuo em relação à constituição das subjetividades e das novas práticas humanas ecologicamente equilibradas conforme as ecologias mental, social e ambiental.

\section{AGRADECIMENTOS}

Agradeço aos professores e aos pós-graduandos vinculados à linha de epistemologia ambi- 
ental do Programa de Pós-Graduação em Meio Ambiente e Desenvolvimento (PPGMADE/ UFPR) com os quais venho mantendo diálogos frutíferos e que proporcionaram, entre outros resultados, o amadurecimento do meu projeto de pesquisa de pós-doutorado atual, bem como esta resenha.

\section{REFERÊNCIAS}

HEYWOOD, Andrew. Ideologias políticas: do feminismo ao multiculturalismo. Tradução Janaína Marcoantonio, Mariane Janikian. São Paulo: Ática, 2010 [1992].

KRENAK, Ailton. Ideias para adiar o fim do mundo. São Paulo: Companhia das Letras, 2019. 